ARTICLE

\title{
Seismic evidence for subduction-induced mantle flows underneath Middle America
}

Hejun Zhu (1) ${ }^{1 凶}$, Robert J. Stern (10) ${ }^{1}$ \& Jidong Yang ${ }^{1}$

Laboratory experiments and geodynamic simulations demonstrate that poloidal- and toroidalmode mantle flows develop around subduction zones. Here, we use a new 3-D azimuthal anisotropy model constructed by full waveform inversion, to infer deep subduction-induced mantle flows underneath Middle America. At depths shallower than $150 \mathrm{~km}$, poloidal-mode flow is perpendicular to the trajectory of the Middle American Trench. From 300 to $450 \mathrm{~km}$ depth, return flows surround the edges of the Rivera and Atlantic slabs, while escape flows are inferred through slab windows beneath Panama and central Mexico. Furthermore, at $700 \mathrm{~km}$ depth, the study region is dominated by the Farallon anomaly, with fast axes perpendicular to its strike, suggesting the development of lattice-preferred orientations by substantial stress. These observations provide depth-dependent seismic anisotropy for future mantle flow simulations, and call for further investigations about the deformation mechanisms and elasticity of minerals in the transition zone and uppermost lower mantle.

\footnotetext{
${ }^{1}$ Department of Geosciences, The University of Texas at Dallas, Dallas, TX, USA. ${ }^{凶}$ email: hejun.zhu@utdallas.edu
} 
M apping mantle flows induced by descending oceanic lithospheres has profound implications for understanding the dynamic, thermal and chemical evolution of subduction systems ${ }^{1,2}$. Two end-member flow circulation patterns have been proposed based on geodynamical, geochemical and seismological observations. The first end-member suggests that the downdip movement of slabs entrains mantle flows to great depths, causing 2-D corner flows perpendicular to the trench in the mantle wedge and beneath the slabs, also known as the poloidal-mode flow ${ }^{3}$. The second end-member suggests that, to preserve the mass displaced by trench migration and slab rollback, 3-D return flows develop in the sub-slab region and surrounding the lateral edge of sinking slabs, also known as the toroidal-mode flow. The toroidal-mode flow typically happens for convergent plate margins with fast trench migration speeds ${ }^{4,5}$, and is important for controlling trench curvature ${ }^{6}$. To date, the behaviors of these two end-members have been extensively investigated using laboratory experiments ${ }^{7,8}$ and mantle flow simulations $^{9,10}$.

Seismic anisotropy is a valuable tool to detect mantle flows in subduction zones ${ }^{11,12}$. Olivine and orthopyroxene, two dominant upper mantle minerals, are intrinsically anisotropic in terms of seismic wavespeeds ${ }^{13,14}$. The strain-induced lattice-preferred orientation (LPO) of olivine leads to the direction and polarization dependence of seismic wavespeeds ${ }^{15}$, which can be detected using shear wave splitting and surface wave tomography. Previous shear wave splitting studies document a trench-parallel pattern beneath the fore-arc and the subducted slab ${ }^{4,16}$, as well as a trench-perpendicular pattern in the back-arc mantle $e^{3}$. However, shear wave splitting measurements represent the path-integrated effects of anisotropy over the entire raypath, leading to poor vertical resolution and controversial interpretations ${ }^{17}$. Surface wave tomography, on the other hand, enables us to constrain depth-dependent azimuthal anisotropy by taking advantage of the dispersive characteristics of Rayleigh and Love waves ${ }^{18-21}$. However, its lateral resolution is typically limited to several hundreds of kilometers due to the use of long-period signals, making it difficult to resolve small-scale features, such as the toroidal-mode mantle flows in the vicinity of sinking slabs. The different lateral and depth resolutions of shear wave splitting and surface wave tomography also make it challenging to reconcile these two independent measurements ${ }^{20,22}$.

In this study, we characterize detailed, depth-dependent seismic anisotropy for the Middle American and Caribbean subduction systems using full waveform inversion ${ }^{23-25}$. The Middle American Subduction Zone (MASZ) is a $2700 \mathrm{~km}$ long, active convergent margin, stretching from Mexico to Costa Rica (Fig. 1), which involves the subduction of the young Rivera and Cocos Plates underneath the North American and Caribbean Plates. Both the Rivera and Cocos Plates are the remnants of the ancient Farallon Plate, which broke into several fragments in the Oligocene $^{26}$. Currently, the $10 \mathrm{Myr}$ oceanic crust of the Rivera Plate is subducting underneath the Jalisco Block of Mexico at a speed of $30 \mathrm{~mm} / \mathrm{yr}$. Along the strike of the Middle American Trench (MAT), the convergence rate of the Cocos Plate relative to the overriding Caribbean Plate increases from $50 \mathrm{~mm} / \mathrm{yr}$ in southern Mexico to $90 \mathrm{~mm} / \mathrm{yr}$ offshore Nicaragua and Costa Rica ${ }^{27}$.

As forming in the Cretaceous, the Caribbean Plate has undergone complicated interactions with the North American, South American and Farallon Plates ${ }^{28}$. It is now bounded to the north by a $1200 \mathrm{~km}$ east-west orientated, left-lateral Septentrional-Oriente Fault System, and to the south by another $>1000 \mathrm{~km}$ long, right-lateral fault, the San Sebastian-El Pilar Fault System. To the west, it is confined by the eastward descending Cocos Plate, and to the east by the westward sinking Atlantic Oceanic lithosphere to form the Lesser Antilles Volcanic Arc
(LAVA). The transition from the subduction of the Atlantic slab to transform motion along the San Sebastian-El Pilar Fault System has been suggested as an example of a Slab-Transform Edge Propagator (STEP) fault ${ }^{29}$. Two tectonic reconstructions have been proposed to explain the origin of the Caribbean Plate: the Pacific ${ }^{30}$ and intra-Americas origin ${ }^{31}$, placing this plate to the west and east of the Farallon Plate in the Cretaceous, respectively. The arcuate-shaped Antilles Subduction Zone is still an enigma in Middle America, which includes the Greater Antilles in the north underneath Hispaniola and Puerto Rico, and the Lesser Antilles in the southeast (Fig. 1). The shallow portion of the subducting slab can be directly inferred from the Wadati-Benioff zone ${ }^{32}$. In the lower mantle, the slabs underneath the Caribbean Plate merge with the Cocos Plate into the prominent fast Farallon anomaly, which has been detected in global tomography models ${ }^{33,34}$.

The Middle American and Caribbean Subduction Zones are ideal locations to investigate the dynamics of subduction systems because of strong variations in the slab morphology ${ }^{35}$, fast trench migration speeds $(20-30 \mathrm{~mm} / \mathrm{yr})^{5}$, the concave-shaped LAVA, as well as heterogeneous geochemical observations in the TransMexico Volcanic Belt (TMVB) ${ }^{36}$ and Central American Volcanic Arc (CAVA) ${ }^{37}$. All these features indicate complex mantle flows and subduction processes underneath Middle America, which are explored by using a new azimuthal anisotropy model $\mathrm{US}_{32}$ in this study.

\section{Results}

3-D azimuthal anisotropy model $\mathrm{US}_{32}$. With the framework of full waveform inversion, we combine three-component shortperiod (15-40 s) body waves with long-period (25-100 s) surface waves to simultaneously constrain deep and shallow structures underneath North and Middle America. The current azimuthal anisotropy model, named $\mathrm{US}_{32}$, is constrained by using 180 earthquakes and 4516 seismographic stations (Supplementary Fig. 2), cumulating in 586,185 frequency-dependent phase measurements. 1579 stations from the USArray Transportable Array, and other permanent and temporary arrays in North and Middle America are used in the inversion, including the Mapping the Rivera Subduction Zone (MARS), Tomography Under Costa Rica and Nicaragua (TUCAN), Meso-America Subduction Experiment (MASE), Veracruz-Oaxaca Subduction (VEOX), etc. Supplementary Table 1 gives the numbers of stations in major contributing arrays (with stations $>30$ ) located in Middle America and used for constructing model US 32 . The current model is the result of 32 preconditioned conjugate gradient iterations. The first 22 iterations are utilized to constrain radially anisotropic model parameters, including horizontally propagating, vertically $\left(\beta_{\mathrm{v}}\right)$ and horizontally $\left(\beta_{\mathrm{h}}\right)$ polarized shear wavespeeds ${ }^{38}$. The last ten iterations are used to further constrain radially ( $L$ and $N$ ) and azimuthally anisotropic $\left(G_{\mathrm{c}}\right.$ and $\left.G_{\mathrm{s}}\right)$ model parameters. These four model parameters are simultaneously updated using the Fréchet derivatives calculated by the adjoint state method, details for constructing the model can be found in $\mathrm{Zhu}$ et al. ${ }^{39}$ and methods.

Figure 2 demonstrates the capability of full waveform inversion to match three-component observed (black) and predicted (red) seismograms for a shallow earthquake that occurred in 2012 underneath Costa Rica, both observations and predictions are bandpass filtered from 25 to $100 \mathrm{~s}$. High-quality data from the high-density USArray enables us to capture complex, triplicated body waves passing through the upper mantle discontinues, and offers us opportunities to harness these signals for delineating detailed structures near these phase transition boundaries. In Fig. 2, three-component body waves, as well as Rayleigh and Love waves are matched very well, suggesting that the mantle 


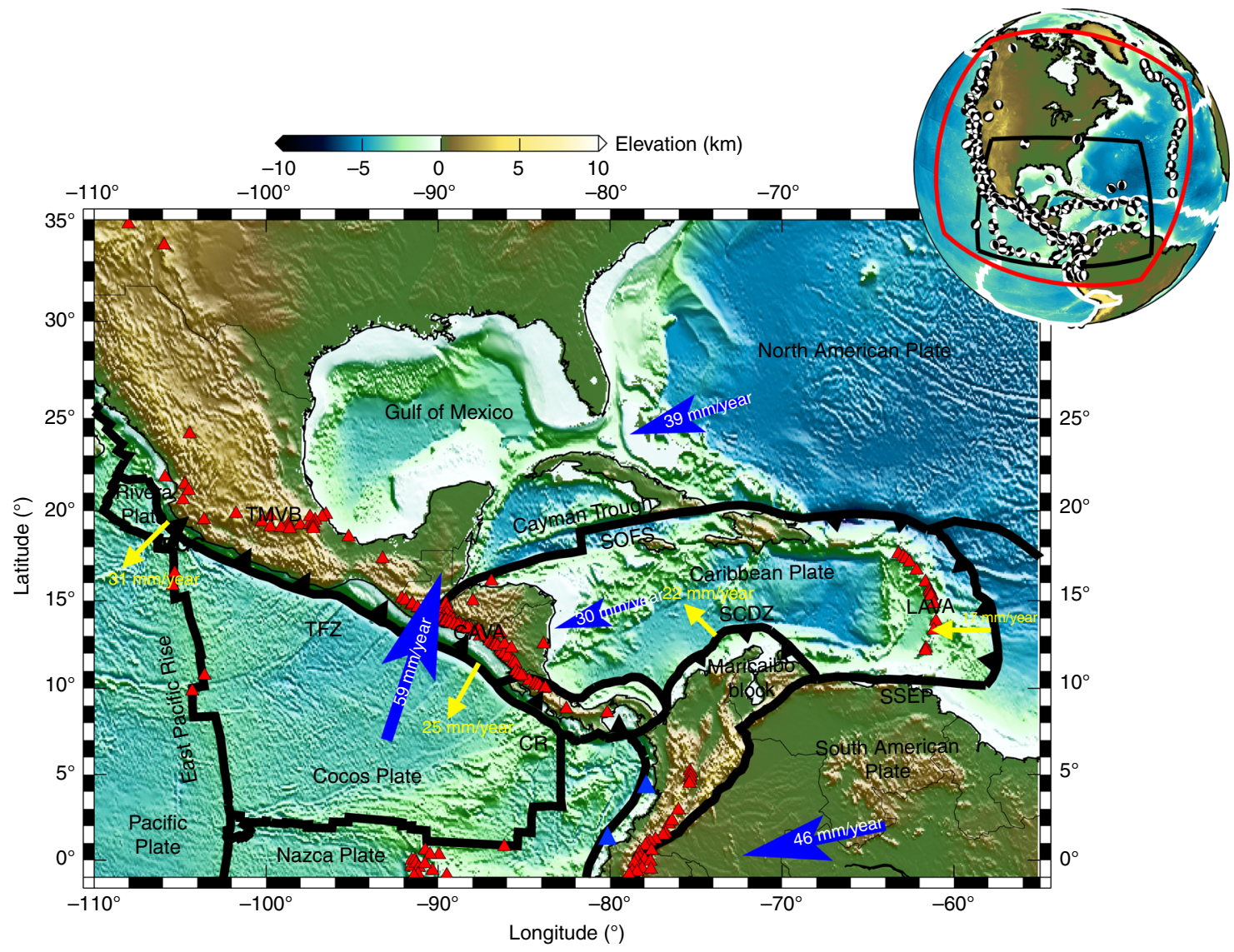

Fig. 1 Tectonic map for the Middle American and Caribbean Subduction Zones. Black lines denote global plate boundaries with triangles showing subduction directions ${ }^{87}$. Red triangles are volcanoes (www.ngdc.noaa.gov/hazard). Blue arrows denote plate motion directions ${ }^{58}$, and yellow arrows show trench migration velocities 55 , all with the Pacific hotspot reference frame. The top right insert shows the location of the study region, with the red box showing the inversion domain. Beach balls denote the moment tensor solutions for earthquakes used in the inversion (www.globalcmt.org). Abbreviations for tectonic structures are: CAVA Central American Volcanic Arc, CR Cocos Ridge, EGG El Gordo Graben, LAVA Lesser Antilles Volcanic Arc, SCDZ Southern Caribbean Deformation Zone, SOFS Septentrional-Oriente Fault System, SSEP San Sebastian-El Pilar Fault System, TFZ Tehuantepec Fracture Zone, TMVB Tran-Mexico Volcanic Belt.

structures underneath Middle America are well constrained in the current model $\mathrm{US}_{32}$. More waveform fittings can be found in Supplementary Note 1, and comparisons with previous tomographic studies can be found in Supplementary Note 6.

Resolution analysis. Analyzing resolution or uncertainty of full waveform inversion is important and challenging, considering computational costs for performing iterative inversion ${ }^{40-43}$. Here, we use the approximated diagonal Hessian and point-spread functions (PSFs) to analyze illumination, resolution, and more importantly tradeoffs among different model parameters for several key features discussed in the following sections. Figure 3 shows the horizontal distribution of the approximated diagonal Hessian underneath Middle America at depths ranging from 100 to $600 \mathrm{~km}$, which is a good indicator for the ray density coverage $^{44}$. Owing to the configuration of stations and earthquakes (Supplementary Fig. 2), the illumination for North America, the MAT and the Lesser Antilles is good at all depth ranges. In contrast, the illumination for the central Caribbean is not as good as other regions, especially at greater depths.

Figure 4 presents one PSF test around the Rivera slab offshore Mexico, a location with interesting features for discussing toroidal-mode mantle flows. In this calculation, a Gaussian anomaly with a half width of $120 \mathrm{~km}$ is added to $G_{\mathrm{s}}$ at a depth of $350 \mathrm{~km}$, and three other model parameters $\left(G_{\mathrm{c}}, L\right.$ and $\left.N\right)$ are held unchanged. Results for this PSF test suggest that there are good constraints for the fast axis orientations at this location, which depend on the ratio between $G_{c}$ and $G_{s}$. For instance, there is limited leakage from $G_{\mathrm{s}}$ to other three model parameters, and the resulting PSF for $G_{\text {s }}$ perturbation is well focused. More PSF tests can be found in Supplementary Note 2. These PSFs give us confidence about the distributions of wavespeeds and anisotropic fabrics at these locations.

Shallow structures. Figure 5 presents horizontal cross sections of isotropic shear wavespeed anomalies and fast axis orientations in model $\mathrm{US}_{32}$ at depths ranging from 50 to $700 \mathrm{~km}$ (more slices can be found in Supplementary Note 3 ). The detailed morphologies of the descending Rivera, Cocos, Caribbean and Atlantic slabs can be examined in the vertical cross sections of Fig. 6 and 3-D isosurface visualization in Fig. 7. At depths shallower than $200 \mathrm{~km}$, anisotropic signatures in model $\mathrm{US}_{32}$ follow wavespeed heterogeneities, tectonic provinces as well as global plate motion directions (Figs. 8 and 9). For instance, the fast directions are mostly perpendicular to the strike of the MAT, reflecting 2-D subduction-induced corner flows at shallow depths ${ }^{3}$. The East Pacific Rise is characterized by prominent slow wavespeed anomalies, and the anisotropic fabrics are aligned perpendicular to the ridge axis, in agreement with seafloor spreading between the Pacific and Cocos Plates. Furthermore, underneath the western Atlantic Ocean, the fast directions are running parallel to the U.S. coastline, suggesting the development of asthenospheric 
a

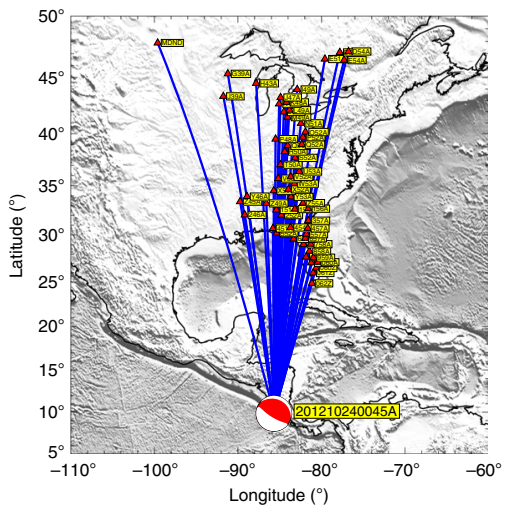

b

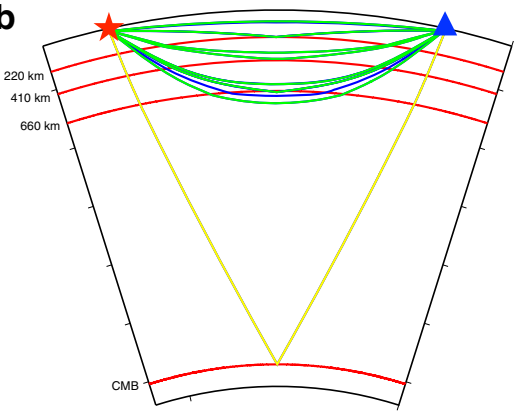

C

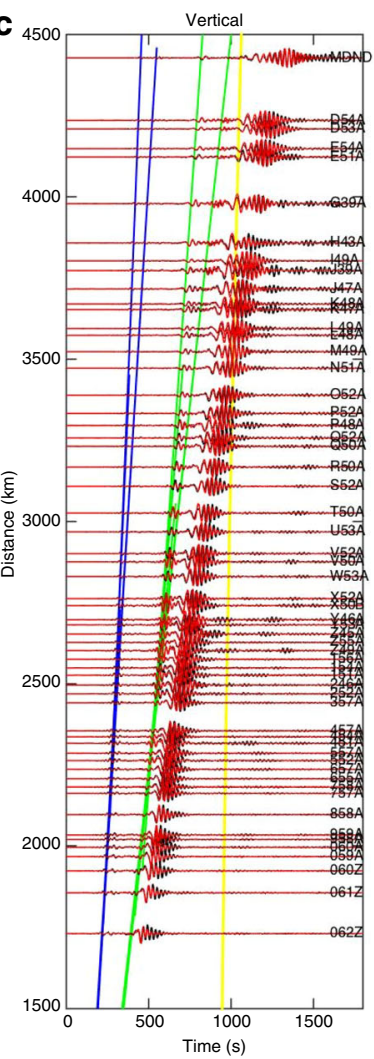

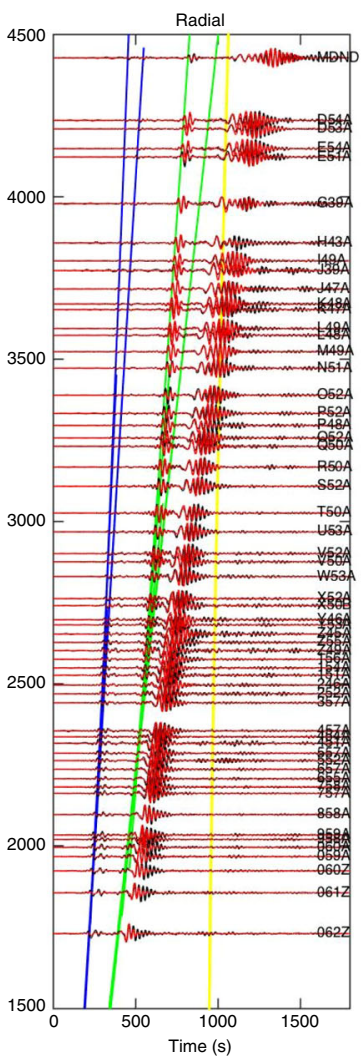

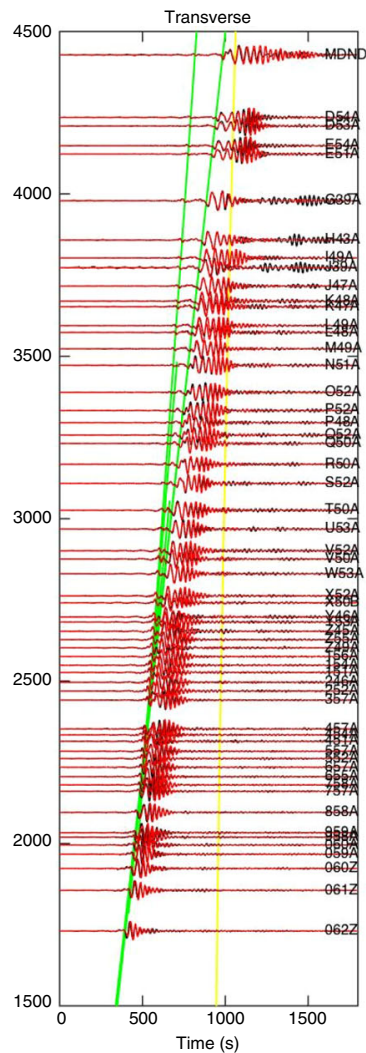

Fig. 2 Comparisons of observed and predicted seismograms from model US $\mathbf{3 2}_{\mathbf{3 2}}$. a The locations of 1 earthquake and 58 stations from the USArray deployed in the eastern U.S. This Mw 6.0 earthquake occurred at a depth of $18.3 \mathrm{~km}$ underneath Costa Rica on October 24th, 2012

(CMTSOLUTION_201210240045A). b The theoretical ray paths of P (blue), S (green), ScS (yellow) phases in the spherical symmetric PREM model ${ }^{88}$, with the epicentral distance equal to $25^{\circ}$. Red lines denote the $220,410,660-\mathrm{km}$ discontinuities and the core mantle boundary. c Compares threecomponent, observed (black) and predicted (red) seismograms for TA stations shown in a. From left to right are vertical, radial and transverse components, respectively. Blue, green and yellow lines denote the theoretical arrival times for P, S and ScS phases from the PREM model. Both observed and predicted seismograms are bandpass filtered from 25 to $100 \mathrm{~s}$.
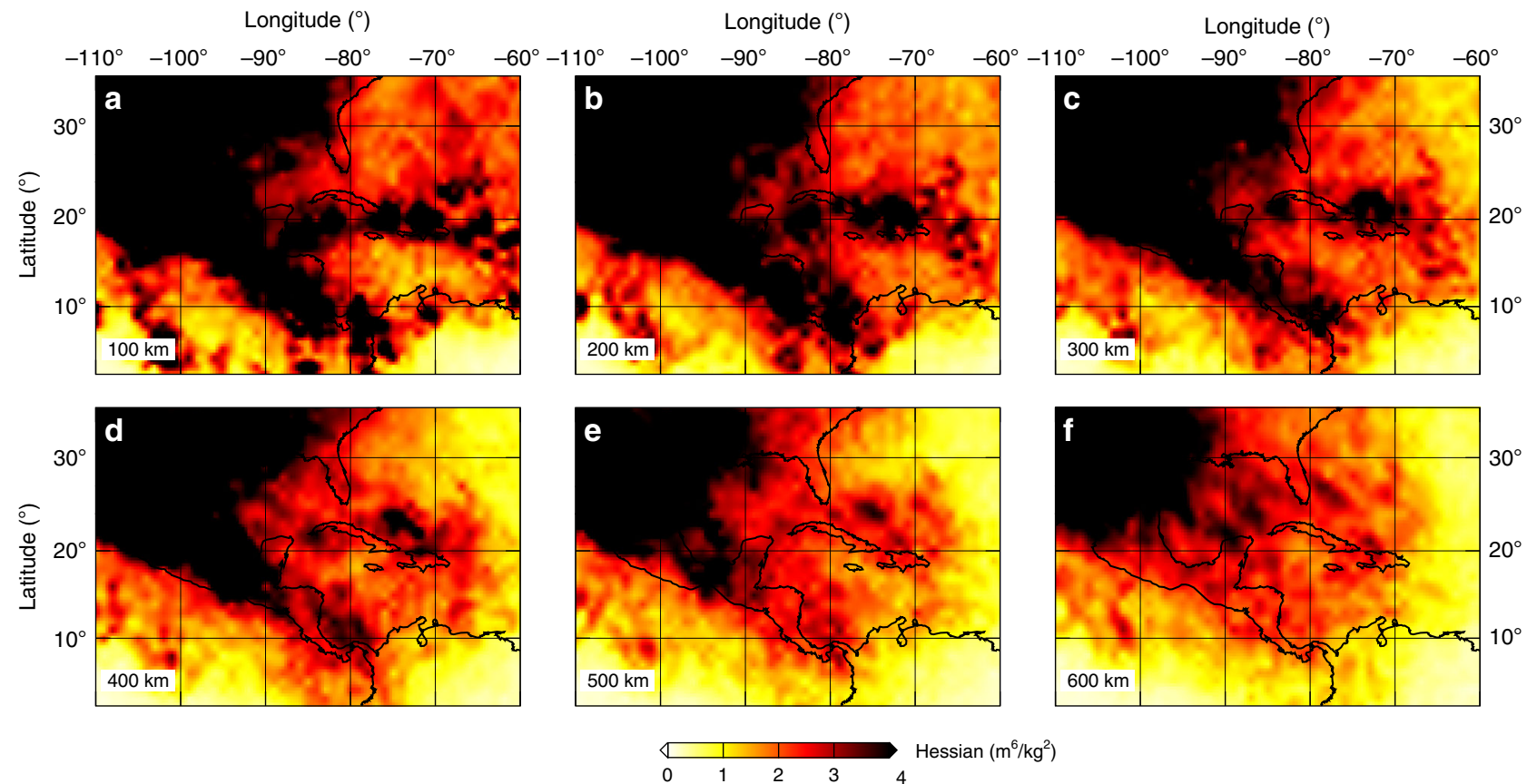

Fig. 3 The distribution of the approximated diagonal Hessian for the study region. a-f Results at depths ranging from 100 to $600 \mathrm{~km}$. Warm color represents good illumination in comparison to cool color. 


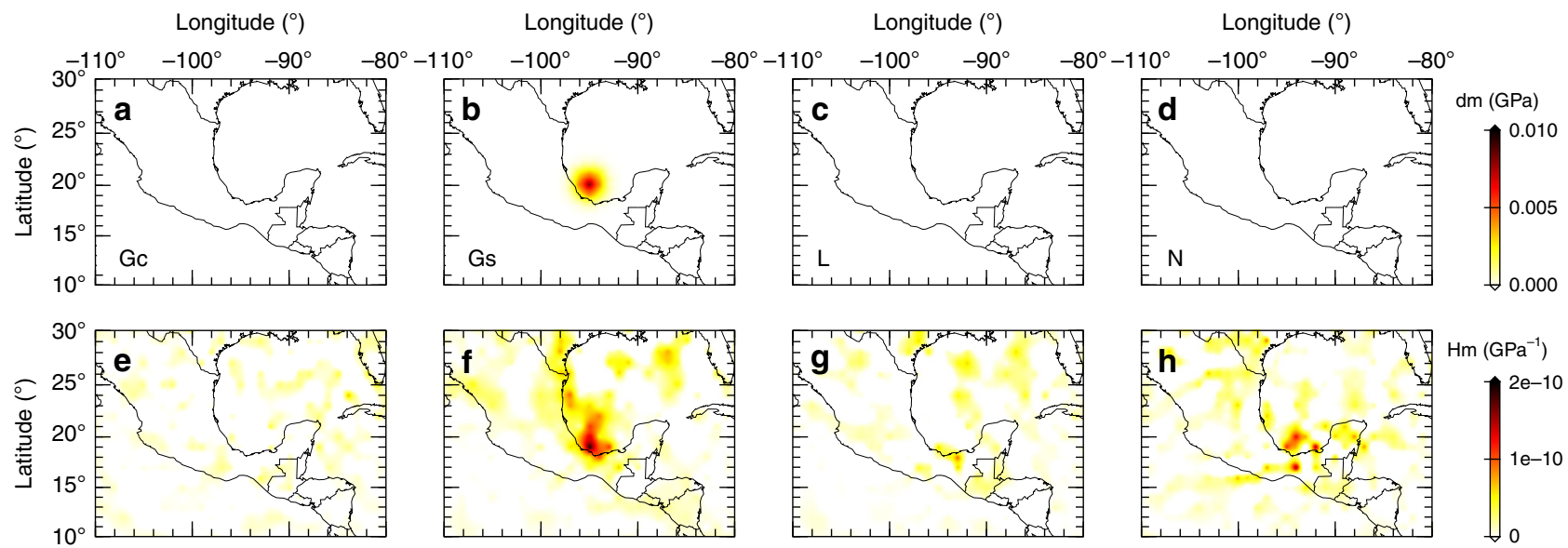

Fig. 4 One point-spread function test at $\mathbf{3 5 0} \mathbf{~ k m}$ offshore Mexico. a-d The input Gaussian perturbations for $G_{c}, G_{\mathrm{s}}, L$ and $N$, respectively. e-h The PSFs with respect to these four model parameters.
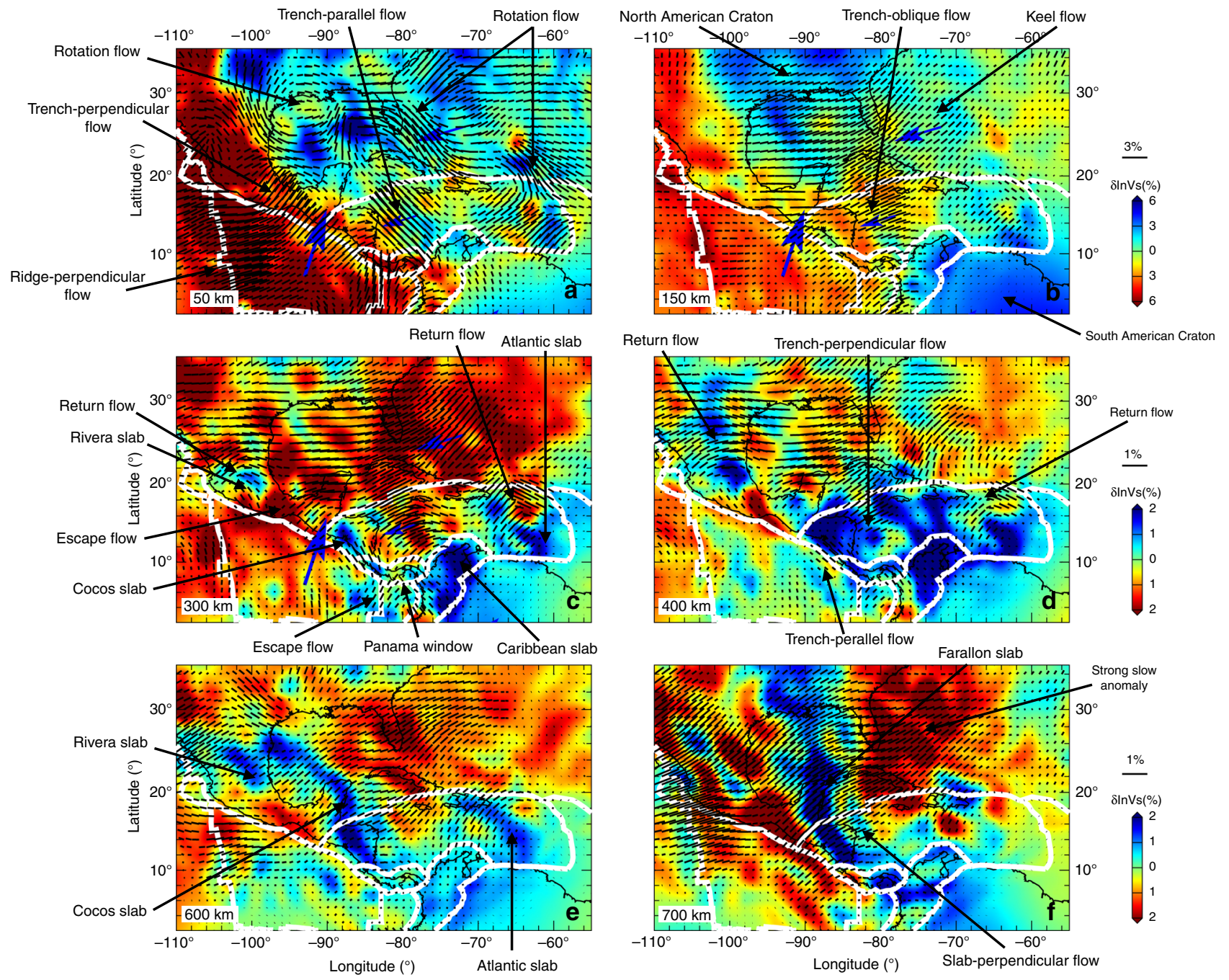

Fig. 5 Horizontal cross sections of relative perturbations in isotropic shear wavespeed and azimuthal anisotropy in model US $\mathbf{S}_{\mathbf{3 2}}$ - a-f Results at depths ranging from 50 to $700 \mathrm{~km}$. 1D reference model STW10589 is used to calculate the relative wavespeed perturbations. The direction and magnitude of the fast axes are given by the orientation and length of the black bars. Key features discussed in the main text are highlighted by arrows, and white lines denote global plate boundaries ${ }^{87}$. Blue arrows at depths ranging from 50 to $300 \mathrm{~km}$ denote plate motion directions ${ }^{58}$. 

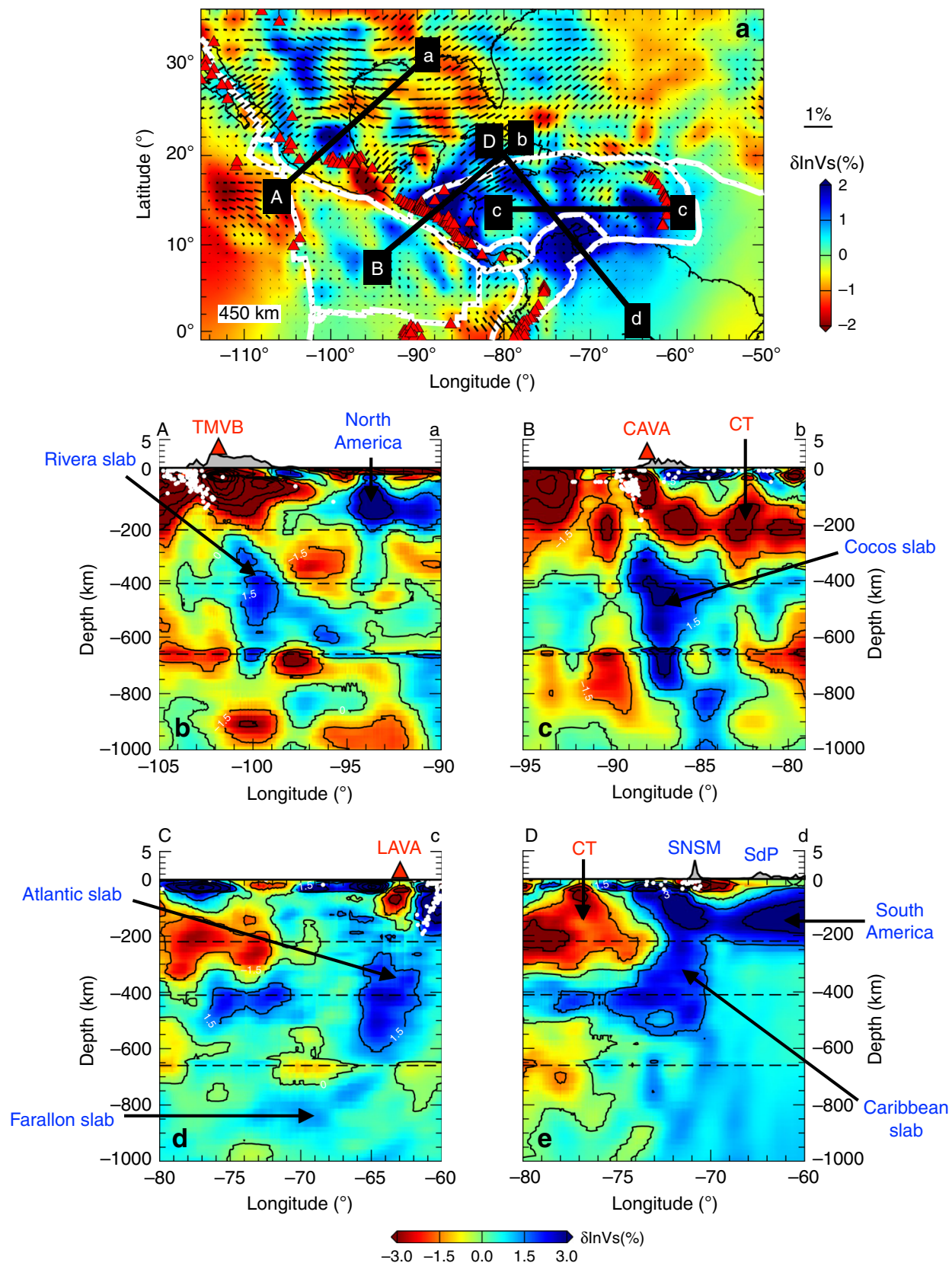

Fig. 6 Vertical cross sections of relative perturbations in isotropic shear wavespeed for the Middle American and Caribbean Subduction Zones. a Shear wavespeed anomalies and fast directions at a depth of $450 \mathrm{~km}$, as well as the locations of four vertical cross sections shown in $\mathbf{b}$-e. The dashed black lines in these cross sections denote the 220, 410 and 660-km discontinuities. Earthquakes with magnitude $>5$ are shown by white circles, and red triangles represent volcanoes. CAVA Central American Volcanic Arc, CT Cayman Trough, SNSM Sierra Nevada de Santa Marta, LAVA Lesser Antilles Volcanic Arc, SdP Serranía del Perijá, TMVB Trans-Mexico Volcanic Belt.

flows surrounding the deep keel of the North American lithosphere $^{45}$, which reaches to around $250 \mathrm{~km}$ (Supplementary Fig. 12). Another potential interpretation of this pattern could be mantle flows affected by the subduction of the Nazca and Farallon slabs as demonstrated in geodynamic flow simulations ${ }^{46,47}$. At depths in excess of $300 \mathrm{~km}$, model $\mathrm{US}_{32}$ exhibits several fast wavespeed anomalies associated with the descending Rivera, Cocos, Atlantic and Caribbean Plates, as well as complicated anisotropic fabrics in their vicinity.

Subduction-induced mantle flows. The narrow Rivera slab is imaged dipping $\sim 40^{\circ}$ northeast underneath the Jalisco Block in
Mexico (profile A-a in Fig. 6). It appears that the Rivera slab is detached from the surface, despite the occurrence of $\mathrm{Mw}>5$ earthquakes at depths shallower than $150 \mathrm{~km}$, which is consistent with global tomography results ${ }^{48}$. Its mantle wedge is characterized by slow wavespeed anomalies, suggesting the ascent of hot asthenosphere from $400 \mathrm{~km}$ towards the TMVB, which might explain uplift and low Bouguer gravity anomalies ( -100 mgal) in this region (Supplementary Fig. 1). The subducted Rivera and Cocos slabs are separated by a slab window, filled with pronounced slow anomalies (<-2\%) from $300 \mathrm{~km}$ down to the transition zone around $12-18^{\circ} N$ (Fig. 5), in agreement with previous body and surface wave tomographic results ${ }^{49,50}$. Furthermore, the fast axes are revealed following the 


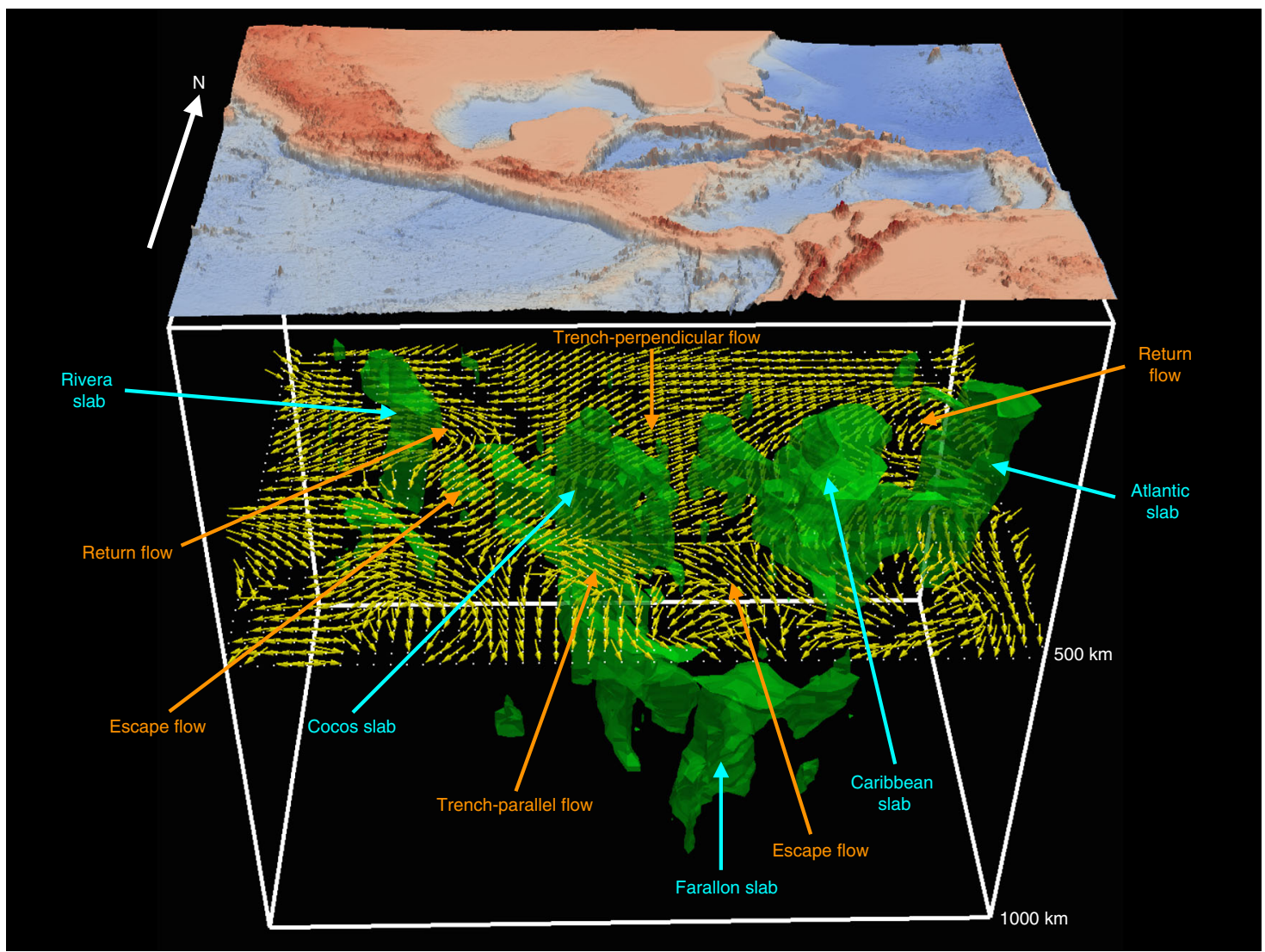

Fig. 7 3-D iso-surface representations of fast wavespeed anomalies with magnitude $>1.5 \%$ (green bodies), and fast axes (yellow arrows) at a depth of $\mathbf{5 0 0} \mathbf{~ k m}$ in model $\mathbf{U S}_{\mathbf{3 2}}$. Topographic variations are superimposed on top of the 3-D iso-surface bodies. Fast anomalies shallower than $250 \mathrm{~km}$, mainly the North and South American lithospheres, are clipped for better visualization of sinking slabs. Cyan arrows are used to highlight slab features, whereas orange arrows are used to denote mantle flow fields.
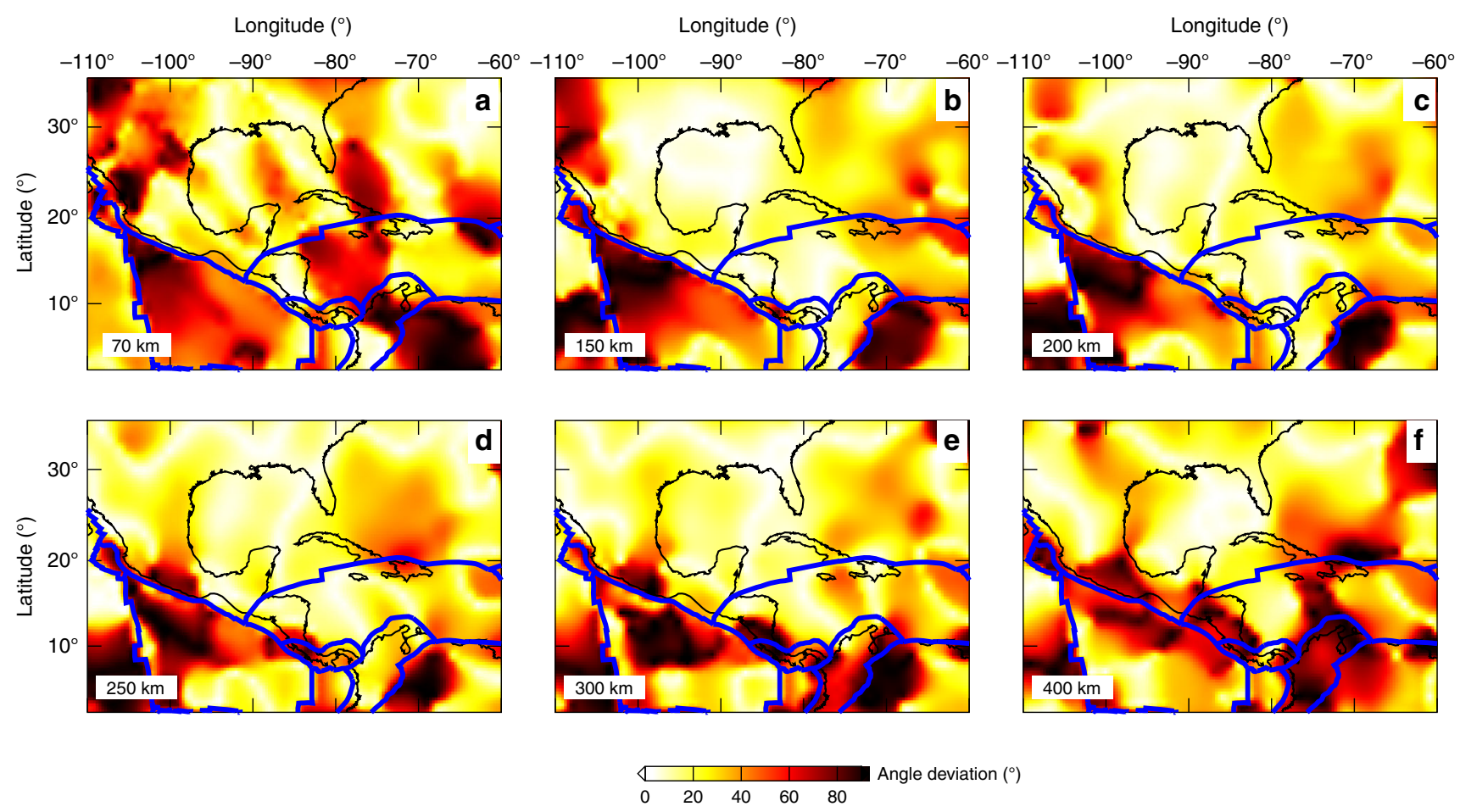

Fig. 8 Angle differences between the fast axis orientations in model US $_{\mathbf{3 2}}$ and the plate motion model NUVEL-1A ${ }^{58}$ with the hotspot reference frame. a-f Results at depths ranging from 70 to $400 \mathrm{~km}$, with warm color representing large angle differences. Blue lines denote the plate boundaries ${ }^{87}$. 


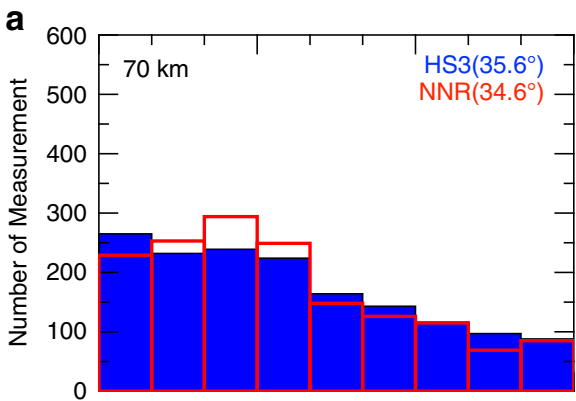

b

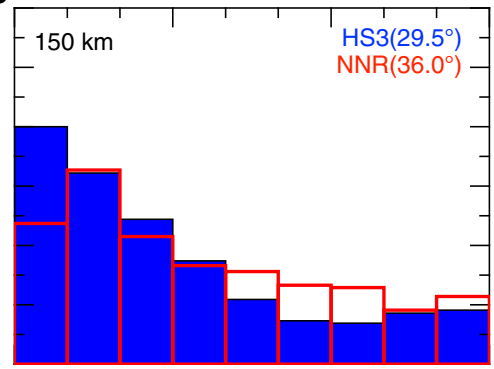

e

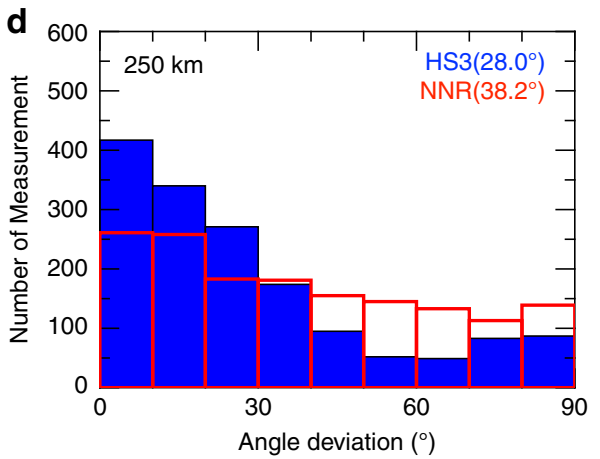

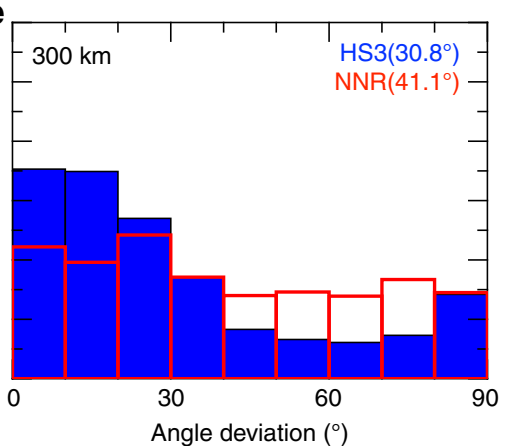

C

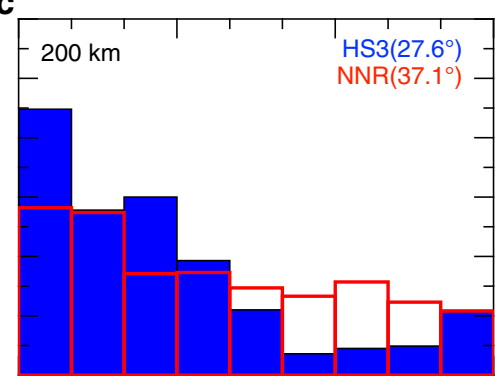

f

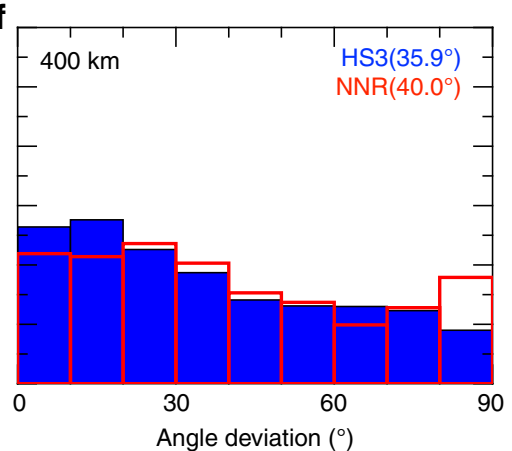

Fig. 9 The histograms of angle differences between the fast axis orientations in model $\mathbf{U S}_{\mathbf{3 2}}$ and the plate motion model NUVEL-1A58. a-f Results at depths ranging from 70 to $400 \mathrm{~km}$. Blue and red histograms are results for the hotspot and no-net rotation reference frames, respectively. Numbers in the brackets to the right corner of each histogram denote mean angle differences between these measurements.

lateral edge of the Rivera slab, and moving across the slab window (Figs. 5 and 7). This pattern reflects the development of return flows surrounding the narrow $(\sim 200 \mathrm{~km})$, fast rollback $(\sim 31 \mathrm{~mm} / \mathrm{yr})$ Rivera slab, as well as escape flows moving across slab windows, owing to large pressure gradients created by slab fragmentations as demonstrated in previous physical and numerical experiments ${ }^{6,7}$. The return flows and slab detachment might contribute to the observed mixed subduction-related calcalkaline rocks with intraplate-like lavas and adakites along the $\mathrm{TMVB}^{36}$, as well as the unusual oblique angle $\left(16^{\circ}\right)$ between the MAT and TMVB.

In profile B-b (Fig. 6) and 3-D visualization (Fig. 7), the Cocos slab plunges $\sim 60^{\circ}$ down to the transition zone underneath Nicaragua and Costa Rica. Its northern boundary is truncated sharply along the extension of the Septentrional-Oriente Fault System (Fig. 5). Flat subduction of the Cocos Plate might exist underneath central Mexico (Supplementary Fig. 14), however, it is still challenging to detect thin, horizontal contrasts at shallow depths using seismic tomography because of its limited vertical resolution. The observation of different dip angles of the Rivera and Cocos slabs along the strike of the MAT is consistent with previous studies from seismicity distribution ${ }^{35}$, local tomography $^{49}$ and receiver functions ${ }^{51}$. The steeper dip of the Cocos slab can be attributed to its older age (23 Myr) and therefore greater density. Similar to the Rivera slab, the Cocos slab is also detached from the surface, with the mantle wedge filled with strong slow seismic anomalies connecting to the CAVA and Cayman Trough. Moreover, the trench-parallel anisotropic pattern is observed in the sub-slab region of the Cocos slab at depths ranging from 300 to $450 \mathrm{~km}$ (Fig. 5). There is a sharp transition in the mantle wedge from the trench-parallel pattern at $50 \mathrm{~km}$ to the trenchperpendicular pattern at greater depths. These complex, depthdependent anisotropic fabrics suggest the development of toroidal-mode flows in the sub-slab region, in response to fast slab rollback $(25 \mathrm{~mm} / \mathrm{yr})$ of the $\mathrm{MAT}^{5}$. Toroidal-mode flows are forced to tilt toward shallower depths in the mantle wedge due to fast slab rollback, and interfere with the corner flows entrained by the downdip motion of the Cocos slab, in agreement with 3-D geodynamic flow simulations ${ }^{9}$. Furthermore, the fast axes in model $\mathrm{US}_{32}$ run across the Panama slab window ${ }^{28}$ between the Cocos and Nazca Plates at 300-400 km depth. This observation supports the hypothesis about the subduction of the Cocos-Nazca Ridge and Galápagos hotspot track in this region ${ }^{28}$, and offering an explanation about the occurrence of Neogene alkaline and arctholeiitic volcanism in Panama ${ }^{52}$.

Underneath the LAVA, the Atlantic lithosphere sinks toward the west with $\sim 50^{\circ}$ dip down to the transition zone (Figs. 6C-c and 7). In contrast to the Rivera and Cocos slabs, the WadatiBenioff zone beneath the LAVA reflects subduction from the surface down to $200 \mathrm{~km}$, with a slow anomaly imaged in the mantle wedge underneath the LAVA. In Fig. 5, there are two fast bodies at 300-400 km depth, one underneath Puerto Rico and the other underneath the southern LAVA, which are separated by a slab window around $16-18^{\circ} \mathrm{N}$. Previous $\mathrm{P}$ wave tomography studies report a similar feature, which was attributed to the subducted North American-South American plate boundary ${ }^{28,53}$. Similar to the anisotropic fabrics observed around the Rivera slab, the fast directions surround the lateral edge of the descending Atlantic lithosphere, and move across the slab window (Figs. 5 and 7). This pattern suggests the development of return flows warping around the narrow, rapidly advancing $(17 \mathrm{~mm} / \mathrm{yr})$ Atlantic slab, which pushes materials within the mantle wedge and induces flows around its edge. The current model fails to delineate east-west oriented anisotropic fabrics along the San Sebastian-El Pilar Fault System as demonstrated in shear wave splitting ${ }^{54}$, suggesting limited resolution due to the lack of stations at this location (Supplementary Fig. 2).

In profile D-d (Fig. 6), the Caribbean slab dips southeast underneath the Southern Caribbean Deformation Zone and Maracaibo Block. Its dip increases from $30^{\circ}$ at depths shallower 
than $200 \mathrm{~km}$ to around $90^{\circ}$ at greater depths, which might be affected by the presence of the thick $(\sim 250 \mathrm{~km})$, craton-like overriding South American Plate. To the northwest, the Cayman Trough is underlain by a triangular slow anomaly $(<-1.5 \%)$ down to $300 \mathrm{~km}$, reflecting strong deformation owing to the relative motion and pull-apart between the North American and Caribbean Plates along the Septentrional Fault System since the Eocene $^{28}$. By pushing mantle materials in the sub-slab region, the fast northwestward rollback of the Caribbean slab $(22 \mathrm{~mm} / \mathrm{yr})^{55}$ might also contribute to the observed northeast-southwest oriented flow field underneath the Caribbean Plate at depths ranging from 300 to $500 \mathrm{~km}$ (Fig. 5).

At $600 \mathrm{~km}$, the fast wavespeed anomalies discussed above merge into a continuous, arcuate-shaped feature surrounding the Gulf of Mexico and Caribbean, which then turns to a northsouth oriented fast Farallon anomaly at $700 \mathrm{~km}^{34}$, stretching from the southern U.S. to South America (Fig. 5). Strong slow anomalies are observed to the west and east of the Farallon slab, which might reflect water entrained down to the transition zone by subduction of the Farallon Plate since the Mesozoic. In comparison to the upper mantle and transition zone, the fast orientations turn perpendicular to the strike of the Farallon anomaly, reflecting poloidal-mode mantle flows in the uppermost lower mantle. This flow field might be driven by strains produced when the Farallon slab penetrated the $660-\mathrm{km}$ discontinuity to enter the lower mantle. This process results in large stresses due to a significant viscosity jump across the $660-\mathrm{km}$ discontinuity ${ }^{56}$, and might produce detectable straininduced seismic anisotropy.

\section{Discussion}

Comparisons with plate motion data. Debayle et al. ${ }^{57}$ concluded that surface wave azimuthal anisotropy models correlate well with global plate motion models ${ }^{58,59}$ for regions with a relatively simple tectonic history, such as oceanic plates. However, for regions with a complicated tectonic history, such as continents, their correlation is much poorer. Figure 8 presents the angle differences between the fast axis orientations in model $\mathrm{US}_{32}$ for the study region with the global plate motion model NUVEL$1 \mathrm{~A}^{58}$ at depths ranging from 70 to $400 \mathrm{~km}$. Both hotspot (Fig. 8) and no-net rotation (Supplementary Fig. 17) reference frames are used for these comparisons. Figure 9 shows the histograms for these angle differences at different depths. Overall, the current seismic model fits plate motion results better for the hotspot reference than the no-net rotation reference at all depths. For instance, from 150 to $300 \mathrm{~km}$, the mean angle differences for the hotspot reference are $<30^{\circ}$, whereas these numbers are $>35^{\circ}$ for the no-net rotation reference. It appears that the fast axis orientations in the current model fit plate motions with the hotspot reference frame better for the North Atlantic and Caribbean. In contrast for the Cocos Plate, the no-net rotation frame fits seismic measurements better. Major differences come from regions with complicated fast axis orientations, especially in the vicinity of subducting slabs, which are not included in large-scale plate motion results.

Implications for mantle flow simulations and deformation mechanisms in the deep Earth. LPO of anisotropic mineral aggregates deformed by dislocation creep is the major cause of seismic anisotropy. Experiments demonstrate that the major minerals within the mantle transition zone and the uppermost lower mantle, such as wadsleyite and bridgmanite, might also be intrinsically anisotropic ${ }^{60,61}$. Diffusion creep or superplasticity is considered as the dominant deformation mechanism in the deep mantle ${ }^{62}$, and this prevents the development of LPO. Therefore, the existence and nature of seismic anisotropy within the transition zone and lower mantle are still highly debated. A recent study reported strong radial anisotropy (up to 2\%) in the vicinity of subducting slabs down to $1000-1200 \mathrm{~km}^{63}$, which raises questions about the deformation mechanisms in the deep Earth. In addition, a number of previous surface wave tomography ${ }^{64,65}$ and shear wave splitting ${ }^{66,67}$ studies speculated about whether or not azimuthal anisotropy exists in the deep mantle, especially around subducted slabs. Anisotropic signatures (with magnitude around 1\%) observed at greater depths in this study provide new seismic evidence for the development of complicated mantle flows induced by subduction systems with fast trench migration speeds and strong variations in slab morphology, such as tearing and detachment. All these seismic observations suggest that dislocation creep might have a more important role in the deep Earth than we thought before. In addition, all interpretations in this article assume that we have A-, C- and E-type LPO for olivine aggregates, other types of LPO, such as type-B fabric affected by water distributions, may change current interpretations ${ }^{14,68}$, especially for the mantle wedge regions.

Furthermore, depth-dependent azimuthal anisotropy observed in this study offers more constraints for investigating the physics of subduction, such as using mantle flow simulations ${ }^{9,10}$ and physical experiments ${ }^{7,8}$. Most recent mantle flow simulations allow us to construct geodynamic models to fit different geophysical and geological observations, such as shear wave splitting 54,69 and plate motions ${ }^{58}$. However, shear wave splitting represents the integrated anisotropic effects over the entire depth range ${ }^{17}$. Therefore, it is a non-unique solution to match splitting measurements through LPO calculations ${ }^{70}$ and flow simulations. The depth-dependent azimuthal anisotropy patterns delineated in this study provide future opportunities to better constrain 3-D deep mantle flows and investigate physical processes through geodynamic modeling.

Misfit function. The details of constructing model $\mathrm{US}_{32}$ can be found in Zhu et al. ${ }^{39}$ Here, we summarize the key components of this study. The spectral-element $\operatorname{method}^{71,72}$ is used to solve the anisotropic/anelastic wave equation, and compute threecomponent synthetic seismograms. Each forward simulation takes 45 minutes using 144 CPU cores, therefore, in total, it took 1.87 million $\mathrm{CPU}$ hours to construct the current model. Frequency-dependent phase measurements for three-component short-period (15-40 s) body waves and long-period (25-100 s) surface waves are combined to simultaneously constrain deep and shallow structures ${ }^{73}$. No crustal correction ${ }^{74,75}$ is required in the inversion owing to the simultaneous update for the crustal and mantle structures. A multi-scale inversion strategy ${ }^{76}$, i.e., starting with long-period signals for long-wavelength updates and gradually incorporating short-period signals to improve resolution, is utilized to mitigate the cycle skipping problem ${ }^{77}$. The total misfit function includes six categories: P-SV body waves on vertical and radial components, and $\mathrm{SH}$ body waves on transverse component; Rayleigh surface waves on vertical and radial components, and Love surface waves on transverse component. A multi-taper technique ${ }^{78}$ is employed to calculate frequency-dependent phase discrepancies between observed and predicted seismograms within automatically selected windows from FLEXWIN ${ }^{79}$. The total misfit is defined as follows

$$
J=\frac{1}{2} \sum_{i=1}^{N_{c}} w_{\mathrm{c}} \sum_{m=1}^{N_{m}} \int w_{m}\left[\frac{\Delta \tau_{m}(\omega)}{\sigma_{m}^{\phi}(\omega)}\right]^{2} \mathrm{~d} \omega,
$$


where $N_{\mathrm{c}}$ denotes the total number of categories, here $N_{\mathrm{c}}=6$ for three-component body and surface wave contributions. $w_{\mathrm{c}}$ is the weighting factor used to balance the magnitudes of each individual category. $w_{m}$ represents the weighting factor used for the multi-taper measurements. Functions $\Delta \tau_{m}(\omega)$ and $\sigma_{m}^{\phi}(\omega)$ represent the frequency-dependent phase anomalies and their associated uncertainties, respectively.

Model parameterization. There are 13 independent model parameters in a typical tomographic study for simultaneously constraining radial and azimuthal anisotropy ${ }^{18,80}$. However, due to the non-uniqueness of geophysical inverse problems and limited sensitivity of seismic data, not all of them can be well resolved in real applications. Previous theoretical studies have suggested that Rayleigh waves are mostly sensitive to $2 \theta$ azimuthal dependent coefficients $G_{\mathrm{c}}$ and $G_{\mathrm{s}}{ }^{81,82}$, whereas Love waves have weak sensitivity to $E_{\mathrm{c}}$ and $E_{\mathrm{s}}$. Here subscripts $\mathrm{c}$ and $\mathrm{s}$ stand for the cosine and sine terms, respectively, and $\theta$ denotes the local azimuth. In this study, we combine three-component surface and body waves to simultaneously constrain four model parameters: two radially anisotropic parameters $L$ and $N$, and two azimuthally anisotropic parameters $G_{\mathrm{c}}$ and $G_{\mathrm{s}}{ }^{39}$.

Thus, the relative perturbation of the total misfit, $\delta J$, can be expressed as the following volume integral

$$
\delta J=\int_{V} K_{L} \delta L+K_{N} \delta N+K_{G_{\mathrm{c}}} \delta G_{\mathrm{c}}+K_{G_{\mathrm{s}}} \delta G_{\mathrm{s}} \mathrm{d} V
$$

These four model parameters are related with the fourth-order elastic tensor $C_{i j}$ as

$$
\begin{aligned}
L & =\frac{1}{2}\left(C_{44}+C_{55}\right), \\
N & =\frac{1}{8}\left(C_{11}+C_{22}-2 C_{12}+4 C_{66}\right), \\
G_{\mathrm{c}} & =\frac{1}{2}\left(C_{55}-C_{44}\right), \\
G_{\mathrm{s}} & =-C_{45} .
\end{aligned}
$$

Misfit gradients. The misfit gradients with respect to the four model parameters $L, N, G_{c}$ and $G_{s}$ can be calculated as follows 83,84

$$
\begin{aligned}
K_{L} & =K_{\mathrm{c}_{44}}+K_{\mathrm{c}_{55}}, \\
K_{N} & =K_{\mathrm{c}_{66}}-2 K_{\mathrm{c}_{12}}, \\
K_{G_{\mathrm{c}}} & =K_{\mathrm{c}_{55}}-K_{\mathrm{c}_{44}}, \\
K_{G_{\mathrm{s}}} & =-K_{\mathrm{c}_{45}} .
\end{aligned}
$$

Here the primary gradient $K_{c i j}$ can be computed via the adjoint state $\operatorname{method}^{85}$ as

$$
K_{c_{i j}}=-\int_{0}^{T} \varepsilon_{i}^{\dagger}(x, T-t) c_{i j}(x) \varepsilon_{j}(x, t) \mathrm{d} t,
$$

where $\varepsilon_{j}$ and $\varepsilon_{i}^{\dagger}$ are the elements of the strain tensors for the forward and adjoint wavefields, respectively.

A preconditioned conjugate gradient method 86 is used to iteratively update the above four model parameters. The final isotropic shear wavespeed $V_{\mathrm{s}}$ and radially anisotropic parameter $\xi$ can be calculated from $L$ and $N$ as

$$
\begin{aligned}
V_{\mathrm{s}} & =\sqrt{(2 L+N) / 3 \rho}, \\
\xi & =N / L .
\end{aligned}
$$

With the distributions of $G_{\mathrm{c}}$ and $G_{\mathrm{s}}$, the peak-to-peak anisotropic strength $G_{0}$ and fast axis direction $\phi$ are computed via

$$
\begin{aligned}
G_{0} & =\sqrt{G_{\mathrm{s}}^{2}+G_{\mathrm{c}}^{2}}, \\
\phi & =\frac{1}{2} \arctan \left(G_{\mathrm{s}} / G_{\mathrm{c}}\right) .
\end{aligned}
$$

\section{Data availability}

All the continuous seismic data are collected from the Incorporated Research Institutions for Seismology (IRIS) Data Management Center (http://www.iris.edu/ds/nodes/dmc/). The digital model for $\mathrm{US}_{32}$ can be downloaded from the attached data file.

\section{Code availability}

The open source spectral-element software package SPECFEM3D_GLOBE and the seismic measurement software package FLEXWIN used in this study are freely available for download via the Computational Infrastructure for Geodynamics (CIG; geodynamics. org). This is UTD Geoscience contribution number 1357.

Received: 26 September 2019; Accepted: 6 March 2020; Published online: 29 April 2020

\section{References}

1. Schellart, W. Kinematics of subduction and subduction-induced flow in the upper mantle. J. Geophys. Res. 109, B07401 (2004).

2. Stegman, D., Freeman, J., Schellart, W., Moresi, L. \& May, D. Influence of trench width on subduction hinge retreat rates in 3-D models of slab rollback. Geochem. Geophys. Geosystems 7, Q03012 (2006).

3. Hall, C., Fischer, K. \& Parmentier, E. The influence of plate motions on threedimensional back arc mantle flow and shear wave splitting. J. Geophys. Res. 105, 28,009-28,033 (2000).

4. Russo, R. \& Silver, P. Trench-parallel flow beneath the Nazca plate from seismic anisotropy. Science 263, 1105-1111 (1994).

5. Long, M. \& Silver, P. The subduction zone flow field from seismic anisotropy: a global view. Science 319, 315-318 (2008).

6. Schellart, W., Freeman, J., Stegman, D., Moresi, L. \& May, D. Evolution and diversity of subduction zones controlled by slab width. Nature 446, 308-311 (2007).

7. Buttles, J. \& Olson, P. A laboratory model of subduction zone anisotropy. Earth Planet. Sci. Lett. 164, 245-262 (1998).

8. Kincaid, C. \& Griffiths, R. Laboratory models of the thermal evolution of the mantle during rollback subduction. Nature 425, 58-62 (2003).

9. Piromallo, C., Becker, T., Funiciello, F. \& Faccenna, C. Three-dimensional instantaneous mantle flow induced by subduction. Geophys. Res. Lett. 33, L08304 (2006).

10. Faccenda, M. \& Capitanio, F. Development of mantle seismic anisotropy during subduction-induced 3-D flow. Geophys. Res. Lett. 39, L11305 (2012).

11. Savage, M. Seismic anisotropy and mantle deformation: what we learned from shear-wave splitting? Rev. Geophys. 37, 65-106 (1999).

12. Park, J. \& Levin, V. Seismic anisotropy: Tracing plate dynamics in the mantle. Science 296, 485-489 (2002).

13. Nicolas, A. \& Christensen, I. in Composition, Structure and Dynamics of the Lithosphere-Asthenosphere system (eds Fuchs, K. \& Froidevaux, C.) 111-123 (AGU, Washington, 1987).

14. Karato, S., Jung, H., Katayama, I. \& Skemer, P. Geodynamic significance of seismic anisotropy of the upper mantle: new insights from laboratory studies. Annu. Rev. Earth Planet. Sci. 36, 59-95 (2008).

15. Zhang, S. \& Karato, S. Lattice preferred orientation of olivine aggregates deformed in simple shear. Nature 375, 774-777 (1995).

16. Smith, G. et al. A complex pattern of mantle flow in the Lau Backarc. Science 292, 713-716 (2001).

17. Silver, P. Seismic anisotropy beneath the continents: probing the depths of geology. Annu. Rev. Earth Planet. Sci. 24, 385-432 (1996).

18. Simons, F., Van der Hilst, R., Montagner, J. \& Zielhuis, A. Multimode Rayleigh wave inversion for heterogeneity and azimuthal anisotropy of the Australian upper mantle. Geophys. J. Int. 151, 738-754 (2002).

19. Debayle, E., Kennett, B. \& Priestiey, K. Global azimuthal seismic anisotropy and the unique plate-motion deformation of Australia. Nature 433, 509-512 (2005).

20. Marone, F. \& Romanowicz, B. The depth distribution of azimuthal anisotropy in the continental upper mantle. Nature 447, 198-201 (2007).

21. Yuan, H. \& Romanowicz, B. Lithospheric layering in the North American craton. Nature 466, 1063-1068 (2010). 
22. Becker, T., Lebedev, S. \& Long, M. On the relationship between azimuthal anisotropy from shear wave splitting and surface wave tomography. $J$. Geophys. Res. 117, B01306 (2012).

23. Tromp, J., Tape, C. \& Liu, Q. Y. Seismic tomography, adjoint methods, time reversal and banana-doughnut kernels. Geophys. J. Int. 160, 195-216 (2005).

24. Tape, C., Liu, Q., Maggi, A. \& Tromp, J. Adjoint tomography of the southern California crust. Science 325, 988-992 (2009)

25. Fichtner, A., Kennett, B., Igel, H. \& Bunge, H. Full seismic waveform tomography for upper-mantle structure in the Australasian region using adjoint methods. Geophys. J. Int. 179, 1703-1725 (2009).

26. Lonsdale, P. Creation of the Cocos and Nazca plates by fission of the Farallon plate. Tectonophysics 404, 237-264 (2005).

27. Manea, V., Manea, M. \& Ferrari, L. A geodynamical perspective on the subduction of Cocos and Rivera plates beneath Mexico and Central America. Tectonophysics 609, 56-81 (2013).

28. van Benthem, S., Govers, R., Spakman, W. \& Wortel, R. Tectonic evolution and mantle structure of the Caribbean. J. Geophys. Res. 118, 3019-3036 (2013).

29. Govers, R. \& Wortel, M. Lithosphere tearing at STEP fault: response to edges of subduction zones. Earth Planet. Sci. Lett. 236, 505-523 (2005)

30. Pindell, J. \& Barrett, S. in The Geology of North America, vol. H, The Caribbean Region (eds Dengo, G. \& Case, J.) 1-55 (Geological Society of America, Boulder, 1990).

31. James, K. Evolution of Middle America and the in situ Caribbean plate model. Geol. Soc. Spec. Publ. 328, 127-138 (2009).

32. McCann, W. \& Pennington, W. in The Caribbean Region (eds Dengo, G. \& Case, J.) 291-305 (Geological Society of America, Boulder, 1990).

33. van der Hilst, R., Widiyantoro, S. \& Engdahl, E. R. Evidence for deep mantle circulation from global tomography. Nature 386, 578-584 (1997).

34. Grand, S., van der Hilst, R. \& Widiyantoro, S. Global seismic tomography: a snapshot of convection in the Earth. GSA Today 7, 1-7 (1997).

35. Pardo, M. \& Suarez, G. Shape of the subducted Rivera and Cocos plates in southern Mexico: seismic and tectonic implications. J. Geophys. Res. 100, 12357-12373 (1995).

36. Ferrari, L., Orozco-Esquivel, T., Manea, V. \& Manea, M. The dynamic history of the Trans-Mexico Volcanic Belt and the Mexico subduction zone. Tectonophysics 522, 122-149 (2012).

37. Hoernle, K. et al. Arc-parallel flow in the mantle wedge beneath Costa Rica and Nicaragua. Nature 28, 1094-1098 (2008).

38. Zhu, H., Komatitsch, D. \& Tromp, J. Radial anisotropy of the North American upper mantle based on adjoint tomography with USArray. Geophys. J. Int. 211, 349-377 (2017)

39. Zhu, H., Yang, J. \& Li, X. Azimuthal anisotropy of the North American upper mantle based on full waveform inversion. J. Geophys. Res. https://doi.org/ 10.1029/2019JB018432 (2020).

40. Bui-Thanh, T., Ghattas, O., Martin, J. \& Stadler, G. A computational framework for infinite-dimensional Bayesian inverse problems, Part I: the linearized case, with application to global seismic inversion. SIAM J. Sci. Comput. 35, A2494-A2523 (2013).

41. Fichtner, A. \& van Leeuwen, T. Resolution analysis in full waveform inversion. J. Geophys. Res. 120, https://doi.org/10.1002/2015JB012106 (2015).

42. Zhu, H., Li, S., Fomel, S., Stadler, G. \& Ghattas, O. A Bayesian approach to estimate uncertainty for full waveform inversion using a priori information from depth migration. Geophysics 81, R307-R323 (2016).

43. Liu, Q. \& Peter, D. Square-root variable metric based elastic full-waveform inversion-part 2 uncertainty estimation. Geophys. J. Int. 218, 1100-1120 (2019).

44. Luo, Y., Tromp, J., Denel, B. \& Calandra, H. 3D coupled acoustic-elastic migration with topography and bathymetry based on spectral-element and adjoint methods. Geophysics 78, S193-S202 (2013).

45. Fouch, M., Fischer, K., Parmentier, E., Wysession, M. \& Clarke, T. Shear wave splitting, continental keels, and patterns of mantle flow. J. Geophys. Res. 105, 6255-6257 (2000).

46. Zhou, Q. et al. Western US seismic anisotropy revealing complex mantle dynamics. Earth Planet. Sci. Lett. 500, 156-167 (2018).

47. Hu, J., Faccenda, M. \& Liu, L. Subduction-controlled mantle flow and seismic anisotropy in South America. Earth Planet. Sci. Lett. 470, 13-24 (2018)

48. Fukao, Y. \& Obayashi, M. Subducted slabs stagnant above, penetrating through, and trapped below the $660 \mathrm{~km}$ discontinuity. J. Geophys. Res. 118 , 5920-5938 (2013).

49. Yang, T. et al. Seismic structure beneath the Rivera subduction zone from finite-frequency seismic tomography. J. Geophys. Res. 114, B01302 (2009)

50. Stubailo, I., Beghein, C. \& Davis, P. Structure and anisotropy of the Mexico subduction zone based on Rayleigh-wave analysis and implications for the geometry of the Trans-Mexico Volcanic Belt. J. Geophys. Res. 117, B05303 (2012).

51. Perez-Campos, X. et al. Horizontal subduction and truncation of the Cocos plate beneath central Mexico. Geophys. Res. Lett. 35, L18303 (2008).
52. Boer, D., Defant, J., Stewert, R. \& Bellon, H. Evidence for active subduction below western Panama. Geology 19, 649-652 (1991).

53. Harris, C., Miller, M. \& Porritt, R. Tomographic imaging of slab segmentation and deformation in the Greater Antilles. Geochem. Geophys. Geosyst. 19, https://doi.org/10.1029/2018GC007603 (2018).

54. Miller, M. \& Becker, T. Mantle flow deflected by interactions between subducted slabs and cratonic keels. Nat. Geosci. 19, https://doi.org/10.1038/ NGEO1553 (2012).

55. Schellart, W., Stegman, D. \& Freeman, J. Global trench migration velocities and slab migration induced upper mantle volume fluxes: constraints to find an Earth reference frame based on minimizing viscous dissipation. Earth-Sci. Rev. 88, 118-144 (2008).

56. Mitrovica, J. Haskell [1935] Revisited. J. Geophys. Res. 101, 555-569 (1996).

57. Debayle, E. \& Ricard, Y. Seismic observations of large-scale deformation at the bottom of fast-moving plates. Earth Planet. Sci. Lett. 376, 165-177 (2013).

58. Gripp, A. \& Gordon, R. Young tracks of hotspots and current plate velocities. Geophys. J. Int. 150, 321-361 (2002).

59. Demets, C., Gordon, R., Argus, D. \& Stein, S. Effect of recent revisions to the geomagnetic reversal time scale on estimates of current plate motions. Geophys. Res. Lett. 21, 2191-2194 (1994).

60. Kawazoe, T. et al. Seismic anisotropy in the mantle transition zone induced by shear deformation of wadsleleyite. Phys. Earth Planet. Inter. 216, 91-98 (2013).

61. Tsujino, N., Yamazaki, D., Seto, Y., Higo, Y. \& Takahashi, E. Mantle dynamics inferred from the crystallographic preferred orientation of bridgmanite. Nature 539, 81-84 (2016).

62. Karato, S., Zhang, S. \& Wenk, H. Superplasticity in the Earth's lower mantle: Evidence from seismic anisotropy and rock physics. Science 270, 458-461 (1995).

63. Ferreira, A., Faccenda, M., Sturgeon, W., Chang, S. \& Schardong, L. Ubiquitous lower-mantle anisotropy beneath subduction zones. Nat. Geosci. 12, 301-306 (2019).

64. Trampert, J. \& Heijst, H. Global azimuthal anisotropy in the transition zone. Science 296, 1297-1299 (2002).

65. Yuan, K. \& Beghein, C. Seismic anisotropy changes across upper mantle phase transitions. Earth Planet. Sci. Lett. 374, 132-144 (2013).

66. Wookey, J., Kendall, J. \& Barruol, G. Mid-mantle deformation inferred from seismic anisotropy. Nature 415, 777-780 (2002).

67. Foley, B. \& Long, M. Upper and mid-mantle anisotropy beneath the Tonga slab. Geophys. Res. Lett. 38, L02303 (2011).

68. Jung, H. \& Karato, S. Water-induced fabric transitions in olivine. Science 293, 1460-1463 (2001)

69. Becker, T., Schulte-Pelkum, V., Blackman, D., Kellogg, J. \& O’Connel, R. Mantle flow under the western Unite States from shear wave splitting. Earth Planet. Sci. Lett. 247, 235-251 (2006)

70. Kaminski, E., Ribe, N. \& Browaeys, J. D-Rex, a program for calculation of seismic anisotropy due to crystal lattice preferred orientation in the convective upper mantle. Geophys. J. Int. 158, 744-752 (2004).

71. Komatitsch, D. \& Tromp, J. Introduction to the spectral-element method for 3-D seismic wave propagation. Geophys. J. Int. 139, 806-822 (1999).

72. Peter, D. et al. Forward and adjoint simulations of seismic wave propagation on fully unstructured hexahedral meshes. Geophys. J. Int. 186, 721-739 (2011).

73. Zhu, H., Bozdağ, E., Peter, D. \& Tromp, J. Structure of the European upper mantle revealed by adjoint tomography. Nat. Geosci. 5, 493-498 (2012).

74. Bozdağ, E. \& Trampert, J. On crustal corrections in surface wave tomography. Geophys. J. Int. 172, 1066-1082 (2008).

75. Lekic, V., Panning, M. \& Romanowicz, B. A simple method for improving crustal correction in waveform tomography. Geophys. J. Int. 182, 265-278 (2010).

76. Bunks, C., Saleck, F. M., Zaleski, S. \& Chavent, G. Multiscale seismic waveform inversion. Geophysics 60, 1457-1473 (1995).

77. Virieux, J. \& Operto, S. An overview of full-waveform inversion in exploration geophysics. Geophysics 74, WCC1-WCC26 (2009)

78. Ekström, G., Tromp, J. \& Larson, E. Measurement and global models of surface wave propagation. J. Geophys. Res. 102, 8137-8157 (1997).

79. Maggi, A., Tape, C., Chen, M., Chao, D. \& Tromp, J. An automated timewindow selection algorithm for seismic tomography. Geophys. J. Int. 178, 257-281 (2009)

80. Yuan, H., Romanowicz, B., Fischer, K. \& Abt, D. 3-D shear wave radially and azimuthally anisotropic velocity model of the North American upper mantle. Geophys. J. Int. 184, 1237-1260 (2011).

81. Smith, M. \& Dahlen, F. The azimuthal dependence of Love and Rayleigh wave propagation in a slightly anisotropic medium. J. Geophys. Res. 78, 3321-3333 (1973).

82. Montagner, J. \& Nataf, H. A simple method for inverting the azimuthal anisotropy of surface waves. J. Geophys. Res. 91, 511-520 (1986)

83. Sieminski, A., Liu, Q. Y., Trampert, J. \& Tromp, J. Finite-frequency sensitivity of body waves to anisotropy based upon adjoint methods. Geophys. J. Int. 171, 368-389 (2007). 
84. Sieminski, A., Liu, Q. Y., Trampert, J. \& Tromp, J. Finite-frequency sensitivity of surface wave to anisotropy based upond adjoint methods. Geophys. J. Int. 168, 1153-1174 (2007).

85. Liu, Q. \& Tromp, J. Finite-frequency sensitivity kernels for global seismic wave propagation based upon adjoint methods. Geophys. J. Int. 174, 265-286 (2008).

86. Fletcher, R. \& Reeves, C. Function minimization by conjugate gradients. Computer J. 7, 149-154 (1964).

87. Bird, P. An updated digital model of plate boundaries. Geochem. Geophys. Geosyst. 4, 1027 (2003).

88. Dziewonski, A. \& Anderson, D. Preliminary reference Earth model. Phys. Earth Planet. Inter. 25, S.297-356 (1981).

89. Kustowski, B., Ekström, G. \& Dziewonski, A. Anisotropic shear-wave velocity structure of the Earth's mantle: a global model. J. Geophys. Res. 113, B06306 (2008).

\section{Acknowledgements}

This work is supported by UTD Faculty startup funding and NSF Grant EAR-1924282. The authors acknowledge the Texas Advanced Computing Center (TACC; https://www. tacc.utexas.edu) for providing computational resources for this study.

\section{Author contributions}

H.Z. collected and analyzed seismic data, and carried out the inversion. R.S. and J.Y. carried out the tectonic interpretation. All authors co-wrote the manuscript together.

\section{Competing interests}

The authors declare no competing interests.

\section{Additional information}

Supplementary information is available for this paper at https://doi.org/10.1038/s41467020-15492-6.

Correspondence and requests for materials should be addressed to H.Z.

Peer review information Nature Communications thanks Jiashun Hu, Qinya Liu and the other, anonymous, reviewer(s) for their contribution to the peer review of this work.

Reprints and permission information is available at http://www.nature.com/reprints

Publisher's note Springer Nature remains neutral with regard to jurisdictional claims in published maps and institutional affiliations.

(c) (i) Open Access This article is licensed under a Creative Commons Attribution 4.0 International License, which permits use, sharing adaptation, distribution and reproduction in any medium or format, as long as you give appropriate credit to the original author(s) and the source, provide a link to the Creative Commons license, and indicate if changes were made. The images or other third party material in this article are included in the article's Creative Commons license, unless indicated otherwise in a credit line to the material. If material is not included in the article's Creative Commons license and your intended use is not permitted by statutory regulation or exceeds the permitted use, you will need to obtain permission directly from the copyright holder. To view a copy of this license, visit http://creativecommons.org/ licenses/by/4.0/.

(C) The Author(s) 2020 